\title{
Pass-Through of SBP Policy Rate to Market Interest Rates: An Empirical Investigation
}

\author{
Mahmood ul Hassan Khan \\ Muhammad Nadim Hanif
}

\begin{abstract}
Market based implementation of monetary policy embeds a swift and complete passthrough of changes in policy rate to market interest rates. This impacts the lending and deposit rates (retail rates) of the banking system. Incomplete and slow pass-through impairs the effectiveness of monetary policy transmission mechanism. This study estimates the degree and the speed of interest rate pass-through in the case of Pakistan. Monthly data on State Bank of Pakistan (SBP) policy rate, money market rates and banks' retail lending/deposit rates from July 2001 to August 2011 is used to estimate an unrestricted autoregressive distributed lag (ARDL) model. The standard ARDL model allows for the estimation of an error correction model, which helps in differentiating short run impact of changes in policy rate from its long run impact on the banks' lending rates. The results indicate that while there is a swift pass-through from the policy rate (T-bill rates and overnight rate) to money market rate, the impact of changes in money market rates on the bank deposit rates is not only sluggish, but also incomplete. However, banks' lending rates on fresh loans are more responsive to changes in money market rates as the banks have the luxury to take into account the changes in opportunity cost of funding.
\end{abstract}

Keywords: Pass-through, market interest rates, monetary policy framework.

\section{Introduction}

Despite active monetary management by the State Bank of Pakistan (the central bank), the economy continued to witness double-digit inflation in recent years (average annual inflation during FY08 to FY11 stood at 14.6 per cent). A quick review of recent monetary policy statements suggests that massive government borrowing from the central bank; swift pass-through of changes in international commodity prices to domestic consumers; upward adjustments in administered prices; and supply side disturbances, diluted the impact of monetary management on ultimate targets. While these factors have definitely contributed to high inflation in recent years, the effectiveness of monetary policy is also questioned as persistently high inflation is difficult to be explained by the supply side factors alone. Thus, it is imperative to investigate the effectiveness of monetary policy at least to the extent of impacting money market rates and banks' lending/deposit rates, which is a key link in transmission mechanism of monetary policy.

Abundant literature on monetary policy reveals that banking system is not a 'neutral conveyor' of changes in monetary policy to the economy (Bernanke and Blinder, 1988; Bernanke and Gertler, 1989; Bernanke, 1993). For example, an increase in monetary policy rate by the central bank may fail to contain excess demand in the economy if the

Mahmood ul Hassan Khan is Senior Joint Director at State Bank of Pakistan, mahmood.khan@sbp.org.pk Muhammad Nadim Hanif is Additional Director at SBP, Karachi, Nadeem.Hanif@sbp.org.pk

The authors are thankful to an anonymous referee and Umar Siddique for their valuable comments on earlier draft of the paper.

\begin{tabular}{llll|l}
\hline Journal of Independent Studies and Research - MSSE & Volume 10 & Number 1 & January 2012 & 97
\end{tabular} 
banks do not adjust their retail rates. This stickiness of banks' retail rates could be attributed to a variety of factors including structure and development level of the financial sector; efficiency of financial markets; degree of competition; funding structure of corporate and household sectors; and access to international resources. These market imperfections are of great importance for developing countries as their financial sectors are generally bank dominated and corporate sector primarily depend on banking system for their long term as well as running finance requirements (Cottarelli and Kourelis, 1994). This is particularly true in case of Pakistan.

The corporate sector borrowed 78.6 per cent of their external funding from the banking system as of end 2010. Moreover, Agha et al. (2005) also found that banking system plays a key role in transmitting changes in monetary policy to aggregate demand through its lending to the private sector.

As a result of continued financial sector reforms and restructuring, the State Bank of Pakistan (SBP) has shifted its focus away from traditional measures of monetary management towards the market-oriented instruments. The efforts have also been made to separate the government debt management from SBP's monetary management as the decision to determine cut-off rate in Treasury Bills auctions is shifted from SBP to the government debt management office (Ministry of Finance). Moreover, the role of SBP policy rate has been strengthened to signal changes in the monetary policy stance by implementing a new framework of interest rate corridor for liquidity management. The recent changes in monetary policy framework of SBP are an indication of strengthening interest rate channel of MTM and in line with the best practices followed by the central banks in advanced countries. Specifically, Goodfriend (1991) noted that official rate is an important lever for central banks that operates through short-term rates and have greater influence on aggregate demand in the economy.

Given the bank-dominated financial sector of Pakistan, the effectiveness of monetary policy critically depends on the pass-through of changes in policy interest rates to banks' lending and deposit rates. It implies that effective monetary management requires credible information on the degree and speed of interest rate pass-through. This would facilitate SBP's decision regarding (magnitude of) change in policy rate to achieve desired impact on bank's retail rates.

The objectives of this study are: (a) to measure the degree and the speed of passthrough of SBP policy rate to banks' retail lending and deposit rates; (b) to explore the possibility of asymmetric pass-through for upward and downward movement in policy rate to bank's lending and deposit rates; and (c) to identify weak links in pass-through mechanism.

The scope of this study is confined to analyze the impact of changes in SBP policy rate on money market rates and retail lending and deposit rates of the banks in Pakistan. This is popularly known as interest rate channel of monetary policy transmission mechanism. In the context of effectiveness of the monetary policy, it is beyond the scope of the study to estimate impact on the amount of the credit to the private sector and on the inflation being the ultimate indicator of the effectiveness of the monetary policy.

Given the background, problem statement, objectives and scope of study in this section, the rest of this study is organized in seven sections. Section 2 provides preliminary

98 January 2012 $\quad$ Volume $10 \quad$ Number $1 \quad$ Journal of Independent Studies and Research - MSSE


review of literature and highlights the contribution of this study to existing literature. This discussion is followed by brief review of SBP monetary policy framework in Section 3 . While theoretical links among key interest rates are explained in section 4 , section 5 describes data and its descriptive statistics. Section 6 discusses methodology used in this study. Discussion on results and asymmetric interest rate pass-through is the subject of Section 7. Final section is for concluding remarks and policy implications.

\section{Literature Review}

Literature on the effectiveness of monetary policy suggests that there is a consensus among economists that monetary policy has strong impact on inflation, while it has a transitory impact, at least in the short run, on economic activities. However, the consensus is based on an assumption that there is a strong and stable relationship between instruments and the ultimate targets of monetary policy through the monetary transmission mechanism (MTM). Moreover, literature on MTM implicitly assumes an instantaneous and complete pass-through of changes in monetary policy instruments to the money market rates and then to the retail rates of banking system (Bernanke and Gertler, 1995; Bernanke and Gilchrist, 1999).

Most of the literature exploring relationship among the instruments and ultimate goal of monetary policy is largely confined to measuring stability of demand for money. This strand of literature largely discards implications of the incomplete and sluggish passthrough of interest rate changes on retail rates of banks in spite of strong theoretical reasoning provided by Bernanke and Blinder (1988); Bernanke and Gertler (1989); and Bernanke (1993). Cottarelli and Kourelis (1994) were the first to explicitly focus on this issue. They explored the link between financial structure and stickiness of banks' retail lending rates. They used monthly data on lending rate, money market rates and discount rates of 31 countries and based their empirical analysis on ARDL modeling. Their results indicated that degree of stickiness was substantially different across countries in the short run. However, the long run multiplier of lending rates, on average, turned out to be $97 \mathrm{bps}$ in response to 100 bps change in market rates.

Another important paper on the response of short-term bank lending rates to policy rate was contributed by Borio and Fritz (1995). The authors provided conceptual framework by relating the notions of opportunity and marginal cost of funding to banks' loan rates, and explicitly recognized the problem of asymmetric nature of interest rate pass-through. A loan rate response function for 12 OECD countries was estimated by using monthly data on key interest rates from January 1984 to July 1994. In their study, policy rate was found to be an important determinant of loan rates both in the short and long run. Their results also indicated that long run responses of lending rate ranged between 80 bps to 110 bps. Cross country differences also came out quite significantly as the short run responses of loan rate and their pattern of adjustments were considerably different. As for asymmetric nature of loan rate responses was concerned, the authors could not reject the null hypotheses of symmetric responses of loan rate for most of the countries over the period of analysis.

Mojon (2000) explored the possibility of different degrees of interest rate pass-through among the 5 economies of European Monetary Union, namely Belgium, France, Germany, Netherlands, and Spain. The results suggested that 'interest rate cycle asymmetry of pass-through' receded with competition in the banking industry. Response

\begin{tabular}{llll|l}
\hline Journal of Independent Studies and Research - MSSE & Volume 10 & Number 1 & January 2012 & 99
\end{tabular} 
of retail rate to the changes in policy rate was found to be sluggish. Moreover, passthrough was relatively swift in case of short-term interest rates compared to the long -term, and there was evidence in favour of asymmetric nature of interest rate passthrough in these countries. Bondt (2002) also confirmed the findings of Mojon (2000).

Tieman (2004) analyzed the impact of changes in the policy rate on the money market rates by using monthly data from January 1995 to February 2004 and by employing ECM. The author found that pass-through of policy rate to money market rate in Romania was consistent with other transition economies in the region. The study also showed that pass-through of policy rate to new bank loans was almost one-to-one, and strengthened over time. Sanusi (2010) estimated the degree of pass-through from changes in Central Bank of Nigeria's official policy rate to the money market and banks' retail rates by using SVAR techniques and monthly data from January 2002 to April 2010. The most important findings of the paper was that the pass-through effect of monetary policy rate on the retail lending and deposits rates actually declined following the implementation of financial sector reforms in 2005.

\subsection{Studies on Pakistan}

Given the role of country specific financial sector developments in determining the speed and degree of interest rate pass-through, the issue has been the subject of at least three studies in our knowledge. Qayyum et al. (2005) was the first to take up this issue and estimated a transfer function by using monthly data on key interest rates from March 1991 to December 2004. Their results indicated that pass-through from T-bill rate to call money rate is almost one-to-one and completed during a month. However, pass-through to weighted average lending rate (WALR) and weighted average deposit rate (WADR) was found to be low.

State Bank of Pakistan (2005) provided empirical evidence on transmission mechanism of change in 6-month T-bill cut-off rate to WALR and WADR of the banking system by estimating an ARDL model upon monthly data from July 1999 to June 2006. The results indicated that short run pass-through is very low as 100 bps increase in T-bills rates lead to only 20 bps rises in WALR during the first month. However, long run coefficient was found to be close to one and it took 5 months to complete the process. Compared to WALR, the pass-through was found to be incomplete in case of WADR as the long run coefficient was 44 bps only.

Khawaja and Khan (2008) also estimated a transfer function by using monthly data from September 2001 to February 2009. Their study focused on KIBOR compared to call money rate in Qayyum et al. (2005). They found that a 100 bps increase in T-bills rate lead to 87 bps rise in KIBOR, 43 bps in WALR and only 16 bps for WADR during a month.

While papers discussed are important contributions to the literature on interest rate pass-through in case of Pakistan, this study extends the earlier work in four aspects. First, it explicitly takes up the issue of asymmetric interest rate pass-through of changes in the policy, which none of the earlier studies on Pakistan considered. Second, in this study we make use of different tenors of KIBOR, which allows us to identify existing rigidities in the market rates as well. The earlier studies on Pakistan were confined to analyze the role of interest rate only. Third, we use weighted average lending rate on both fresh and outstanding loans to segregate the impact of change in policy rate on

\begin{tabular}{l|lll}
\hline 100 & January 2012 & Volume 10 & Number $1 \quad$ Journal of Independent Studies and Research - MSSE
\end{tabular} 
new loan contracts and the old ones. The same bifurcation is also maintained in case of bank deposits. And, finally the study incorporates a section on monetary policy framework to explain major changes over the period of estimation. Keeping these changes in mind, we take into account the weighted average overnight rate as the SBP uses an implicit and/or explicit interest rates corridor since July 2005.

\section{Monetary Policy Framework in Pakistan}

In line with the developments taking place at international front, the monetary policy framework of SBP has witnessed substantial changes. The monetarist view that monetary policy is a prime source of the business cycle and a constant monetary growth rule can be followed in a bid to smooth out fluctuations in output growth, dominated the monetary policy framework of SBP till late 1990s. A key assumption of monetarism that there exists a stable relation between monetary aggregates and inflation was tested by a number of researchers in case of Pakistan. We had evidence of stable money demand function in studies for Pakistan using data up to late 1990s (Sassanpour and Moinuddin, 1993; Khan, 1994; Khan et al., 2000). In these settings, SBP had been targeting broad money supply (M2) growth within a desirable limit - determined on the basis of an estimated money demand function, considering government's economic growth and inflation targets for the year. For targeting inflation, M2 was used as an intermediate target and $\mathrm{MO}$ had been used as an operational target. SBP followed reserve money program to estimate the desired size of open market operations. However, structural changes both in the economy and financial market, financial innovations and technological advancements significantly weakened the relation between inflation and broad money supply (Moinuddin, 2007; Hanif et al., 2010).

Pakistan has slowly moved from monetary aggregate targeting to an eclectic approach. National Credit Consultative Council has been restructured into a Private Credit Advisory Committee (PCAC) and rather than announcing the detailed credit plan for a year, SBP started giving just an 'indicative' M2 target based upon government announced growth and inflation targets and assessing the trends of net domestic assets (NDA) and net foreign assets (NFA). Exchange rate is now market driven. SBP has been pursuing the goal of price stability without being prejudice to economic growth. For some years, when M2 growth was used an indicative target, it served as an intermediate target, however, SBP has abandoned to target M2 growth since FY10. Furthermore, the operational target has been transformed from reserve money to the overnight (as it is generally recognized that central banks can better control the very short end of the yield curve) money market repo rate (with the movement of the overnight money market repo rate restricted within the corridor of SBP's overnight reverse repo rate as the ceiling and SBP overnight repo rate as the floor - the gap between the ceiling and floor is currently 300 bps) effective from August 2009. The movement of overnight money market repo rate is restricted within the 'corridor' by conducting open market operations (OMOs) for liquidity management. Monetary policy stance is signaled through change(s) in discount rate. The role of cash reserve requirements and statutory liquid ratio has been minimized.

A variety of economic and monetary indicators are used to obtain information on how and when SBP may need to adjust the policy stance in order to get closer to achieve the ultimate goal of price stability without being prejudice to economic growth. These indicators include yield curve, weighted average lending/deposit rates, various measures of core inflation, and (some proxy of) output gap. Information on broad money and the reserve money is also used in addition to their disaggregated levels like NDA and NFA.

\begin{tabular}{llll|l}
\hline Journal of Independent Studies and Research - MSSE & Volume 10 & Number 1 & January 2012 & 101
\end{tabular} 
The underlying factors responsible for changes in NDA and NFA are also minutely analyzed. Monetary policy is announced by SBP on every two months. In addition to time release of relevant data on its website, a detailed information set used to guide the policy decision is also released twice a year to public.

\section{Theoretical links among the Key Interest Rates}

Commercial banks are to maximize their profits. In this process, lending rate is primarily determined by the opportunity cost of extending loans. One of the most widely used indicators of opportunity cost is the money market rate (Borio and Fritz, 1995). In practice, the banks generally have the opportunity to place their funds in the money market instead of extending loans to businesses. At the same time, money market rate also represents the marginal cost of funding for the banks as a bank can borrow from the money market at margin for onward lending. It may be noted that money market rate is beyond the control of a specific bank because a single bank is generally a price taker in the money market.

The policy rate is a key indicator of monetary policy stance and significantly impacts the spectrum of interest rates in the economy. It also represents the opportunity cost of funding for banks. In general, banks are allowed to secure funding at policy rate from the central bank in case of liquidity shortages. In these setting, Borio and Fritz (1995) argued that profit maximizing conditions require that banks' lending rates must reflect the changes in opportunity cost of funding. Specifically, in a perfectly competitive environment, there should be one-to-one relationship between lending rate and opportunity cost of funding, if credit risk premium is held constant.

\subsection{Asymmetric and Sluggish Response of Lending Rate}

In simple terms, asymmetric implies that lending and deposit rates' response differs with respect to increase and decrease in the policy rate, while stickiness (or sluggish response) means that change in banks' retail rate is less than that of the policy or money market rates. It is generally observed that stickiness in deposit rates limits the response of lending rates to changes in money market rates. Other factors that limit the passthrough of changes in money market to lending rates include level of competition in the banking sector, efficiency of money market and operating cost of banks (Cottarelli and Kourelis, 1994).

Table 1: Description of Key Variables

\begin{tabular}{l|l} 
Name & Description \\
\hline PR & SBP Policy Rate \\
TBCO & Six-month T-Bill Cut off Rate \\
ONR & Weighted Average Overnight Repo Rate \\
LRO & Weighted Average Lending Rate-Outstanding \\
LRM & Weighted Average Lending Rate-Marginal \\
DRO & Weighted Average Deposit Rate-Outstanding \\
DRM & Weighted Average Deposit Rate-Marginal \\
K1W & One-week Karachi Interbank Offered Rate \\
K1M & One-month Karachi Interbank Offered Rate \\
K3M & Three-month Karachi Interbank Offered Rate \\
K6M & Six-month Karachi Interbank Offered Rate
\end{tabular}

As for asymmetric impact of changes in market rates on lending rate is concerned, there are several factors which affect the degree of response in decreasing and increasing interest rate environment. The most important one is composition of loan contracts

\footnotetext{
102 January $2012 \quad$ Volume $10 \quad$ Number $1 \quad$ Journal of Independent Studies and Research - MSSE
} 
offered by banks. If loan rates are fixed over as medium to long term, banks will be taking the hit of foregone income due to inability of reprising loans at higher rate in an increasing interest rate scenario. This may lead to relatively swift increase in lending rates on the new loans. Besides this, the demand for banks loans may also change in response to developments taking place in the economy. It is generally observed that elasticity of bank loans to lending rate declines during the recession and opposite is the case when economic activities are booming (Borio and Fritz, 1995).

\section{Descriptive Statistics of Key Variables}

In this study, we used monthly time series data on the policy rate, KIBOR of different tenors, weighted average lending rate, and weighted average deposit rate of the banking system from July 2001 to August 2011 (Table 1). Before rigorous analysis based upon econometric exercise, it is instructive to look at descriptive statistics of key variables for the analysis.

\subsection{Lending Rate}

While analyzing pass-through of policy rate to retail lending rates, an important issue is the choice of specific lending rate. We have to resort to some sort of representative lending rate for the banking system. In case of Pakistan, we have the opportunity to use two types of weighted average lending rates (LR), i.e., LR based on outstanding amount of (stock of) loans, and the loans disbursed during the month. Descriptive statistics of both marginal and outstanding lending rates indicate that marginal lending rates (LRM) relatively exhibit more fluctuations compared to lending rates on outstanding loans (LRO).

\subsection{Deposit Rates}

Like lending rates, we have two types of average deposit rates, i.e., weighted average deposit rate based on fresh deposits (DRM) mobilized during the month and the weighted average rate paid on outstanding deposits (DRO). Descriptive statistics in Table 2 suggest that returns on fresh deposits appear to be more responsive compared to average rates on outstanding deposits. Both the range and standard deviation of fresh deposits are larger than the corresponding statistics for outstanding deposits.

Table 2: Descriptive Statistics of Key Interest Rates

\begin{tabular}{|c|c|c|c|c|c|c|c|c|c|c|c|}
\hline & \multicolumn{2}{|c|}{ ending Rates } & \multicolumn{2}{|c|}{ Deposit Rates } & \multicolumn{4}{|c|}{ Market Rate-KIBOR } & \multicolumn{3}{|c|}{ Proxies for Policy Rate } \\
\hline & LRM & $\overline{\mathrm{LRO}}$ & $\overline{D R M}$ & DRO & $\mathrm{K} 1 \mathrm{~W}$ & $\mathrm{~K} 1 \mathrm{M}$ & K3M & $\mathrm{K} 6 \mathrm{M}$ & PR & TBCO & ONR \\
\hline Mean & 10.8 & 11.5 & 5.0 & 4.4 & 8.6 & 8.7 & 8.9 & 9.1 & 10.3 & 8.5 & 9.3 \\
\hline Median & 11.0 & 11.3 & 5.0 & 4.2 & 9.5 & 9.4 & 9.7 & 10.0 & 9.0 & 8.8 & 9.1 \\
\hline Maximum & 15.5 & 14.7 & 9.5 & 7.0 & 14.0 & 14.3 & 15.5 & 15.7 & 15.0 & 14.0 & 13.7 \\
\hline Minimum & 4.6 & 6.4 & 1.2 & 1.2 & 1.5 & 1.3 & 1.4 & 1.6 & 7.5 & 1.3 & 1.4 \\
\hline Range & 10.9 & 8.2 & 8.3 & 5.8 & 12.5 & 13.0 & 14.1 & 14.1 & 7.5 & 12.7 & 12.3 \\
\hline Std. Dev. & 3.1 & 2.3 & 2.2 & 1.8 & 3.8 & 3.9 & 4.0 & 3.9 & 2.5 & 3.9 & 3.0 \\
\hline Obs. & 122 & 86 & 122 & 86 & 120 & 120 & 120 & 120 & 122 & 122 & 86 \\
\hline
\end{tabular}

\subsection{Policy Rate}

SBP sets its overnight reverse repo rate (also known as discount rate) at which banks can borrow funds from the central bank. Another important proxy for the policy rate is the weighted average overnight rate (WAONR).

Another important interest rate, which is widely confused with the SBP policy rate, is the cut-off T-bills rate (Figure 1). Trends in various interest rates reveal that confusion 
was not entirely misplaced. Specifically, the spread between the weighted average lending rates on fresh loans (WALRM) and the policy rate remained negative from July

Figure 1: Trends in Policy Rates

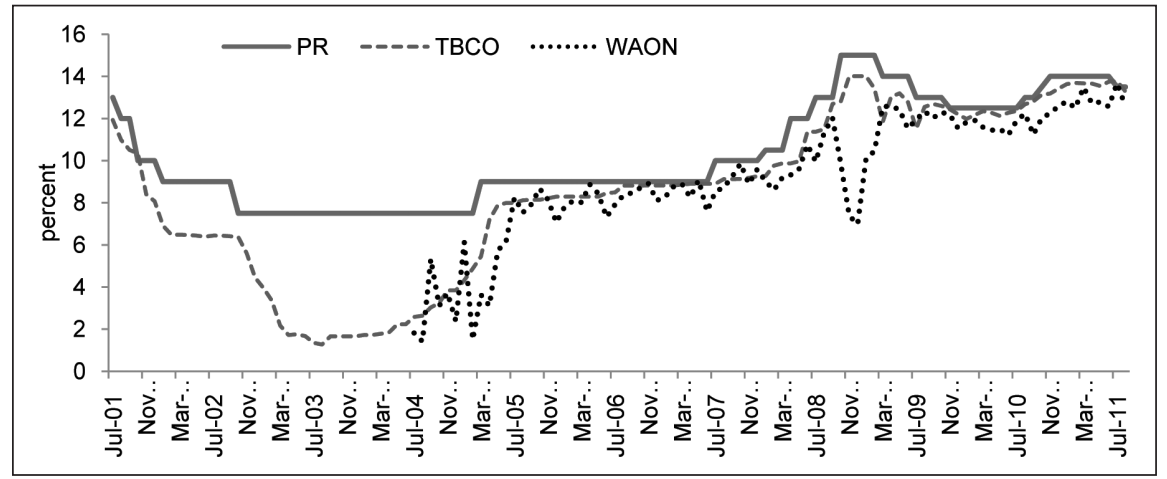

Figure 2: Spread between Lending and Policy Rates

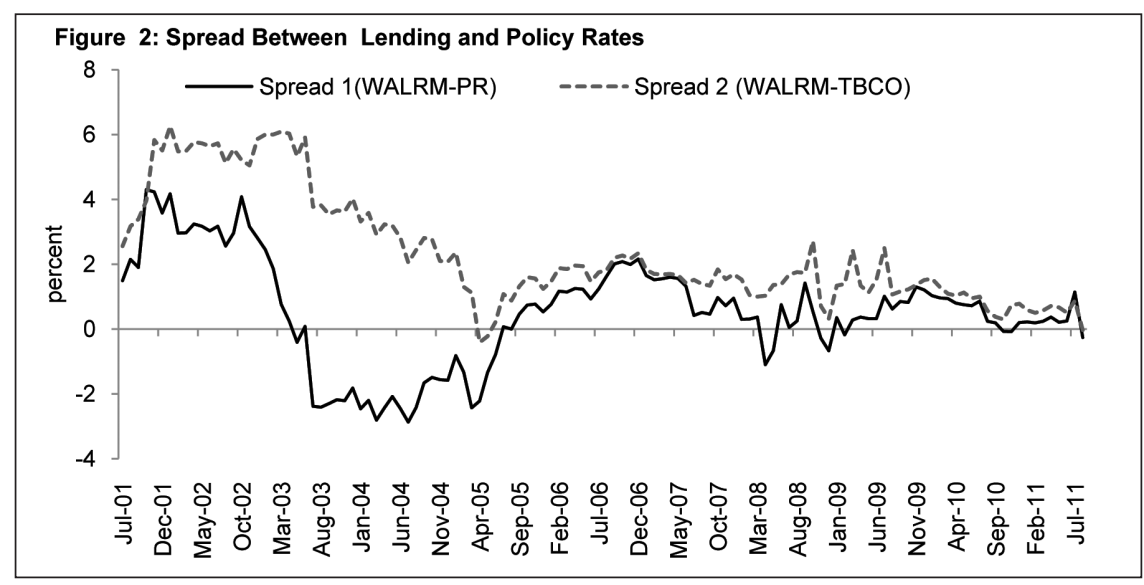

2003 to July 2005 (Figure 2). Persistence of negative spread for almost two years reveals that the policy rate was made ineffective during that period by not moving it and focusing on cut-off T-bill rate as monetary policy signal of SBP. Perhaps this is the reason that all three earlier studies (Qayyum et al. 2005; State Bank of Pakistan, 2005; Khawaja and Khan, 2008) measuring pass-through of interest rates used 6-month Tbill rate as the exogenous variables in their models. Keeping all these issues in mind, all three rates, namely the SBP policy rate, WAONR, and 6-month T-bill cut-off rate, are used to analyze their impact on the retail rates of the banking system.

\subsection{Money Market Rate}

The importance of money market rates in the monetary transmission mechanism can hardly be over emphasized as: (a) changes in policy directly influence the money market rate; and (b) these rates are an important determinant of cost of marginal funding for the scheduled banks.

104 January 2012 $\quad$ Volume $10 \quad$ Number $1 \quad$ Journal of Independent Studies and Research - MSSE 
Although all the money market rates follow similar pattern, the choice of specific rate may influence the overall findings as the volatility of different tenors' money market rates sometimes differ considerably. Being cognizant of this issue, we use KIBOR of four different tenors ranging from one week to 6 months. Descriptive statistics in Table 1 reveal that short-term KIBOR (one week and one month) exhibits slightly lower volatility than the medium-term tenors KIBOR.

\section{Empirical Model}

One of the most important techniques for analyzing the dynamics of interest rate passthrough is the autoregressive distributed lag (ARDL) model (Pesaran et al., 2001). This technique has advantage over other specifications including unrestricted Vector Error Correction, Structural Vector Auto-regression, and other single equation approaches to co-integration. This technique also allows the estimation of short and long run relationships even if the underlying variables are not integrated of the same order, and the sample is small.

Following Pesaran et al. (2001), a conditional ARDL error correction specification of order $(1,1)$ to measure the impact of money market rate $(M M R)$ upon marginal lending rate (as an example) is as follow:

$$
\Delta L R M_{t}=\beta_{0}+\beta_{1} M M R_{t-1}+\beta_{2} L R M_{t-1}+\beta_{3} \Delta L R M_{t-1}+\beta_{5} \Delta M M R_{t}+\beta_{5} \Delta M M R_{t-1}+\mu_{t}
$$

Where LRMt is the weighted average lending rate, MMRt is the money rate, ? stand for difference, and $\mu$ t is an error term. In estimation, structural lags in above specification are established by using information criteria like Akaike's Informational Criterion (AIC), Schwartz Bayesian Criterion (SBC) and other diagnostics of the residuals. Once the optimal lag structure is identified, the specification is tested for the existence of the long run relationship (i.e., co-integration) by using "bounds test". Specifically, the Wald test is used to test for the long run relationship by imposing restrictions on above specification. The above specification implies that following hypothesis will be a test for co-integration.

Null Hypothesis: $H_{0}: \beta_{1}=\beta_{2}=0$, i.e., there is no long run relationship.

Alternative Hypothesis: $H_{1}: \beta_{1} \neq \beta_{2} \neq 0$, i.e., there is a long run relationship.

Restrictions under Null Hypothesis are evaluated by computing F-Statistic and using critical values for Lower and Upper bounds provided by Pesaran et al. (2001).

In case of evidence in favour of co-integration, the ARDL specification can be used to obtain conditional long run model by assuming that all deviations (difference terms) are equal to zero.

$$
L R M_{t}=\gamma_{0}+\gamma_{1} M M R_{t}
$$

Simple algebra also indicates that long run coefficient can easily be estimated from the conditional ARDL-ECM estimated earlier. 


\section{Results}

A good starting point for estimation is to explore time series properties of interest rates. We use Augmented Dickey-Fuller (ADF) test to explore the presence of unit root in the series. The test statistics for each series reported in Table 3 shows that all the interest rate series exhibit a unit root process and are integrated of order 1 . Time series properties, of the series of interest we have, allow the estimation of conditional ARDL-ECM, as it requires that dependent variable should be integrated of order 1 for testing the existence of long run relationship, while there is no restriction on the order of integration of the regressors (i.e. explanatory variables) to be necessarily I(1).

Table 3: Results of ADF Unit Root Test

\begin{tabular}{lcccccccc}
\hline & \multicolumn{9}{c}{ Level } & & & & \multicolumn{2}{c}{ 1st Difference } \\
\cline { 2 - 5 } Variable & ADF & Intercept & Trend & Lags & ADF & Intercept & Trend & Lags \\
\hline TBCO & -0.5979 & Yes & No & One & -8.3255 & Yes & No & Zero \\
ONIR & -1.7695 & Yes & No & Zero & -9.9260 & Yes & No & One \\
ONR & -2.6770 & Yes & No & Zero & -14.1110 & Yes & No & Zero \\
LRO & -2.4459 & Yes & No & One & -2.5847 & Yes & No & Zero \\
LRM & -1.9275 & Yes & No & Four & -3.0530 & Yes & No & Three \\
DRO & -1.7839 & Yes & No & One & -6.0499 & Yes & No & Zero \\
DRM & -0.6636 & Yes & No & Zero & -12.7272 & Yes & No & Zero \\
K1W & -1.2620 & Yes & No & Zero & -5.3075 & Yes & No & Three \\
K1M & -0.5900 & Yes & No & One & -8.4796 & Yes & No & Zero \\
K3M & -0.8111 & Yes & No & One & -7.1499 & Yes & No & Zero \\
K6M & -0.8836 & Yes & No & One & -6.8353 & Yes & No & Zero
\end{tabular}

Critical values at 1, 5 and 10 percent level of significance are 3.4865, 2.8861 and 2.5799 respectively.

\subsection{Pass-through of Policy Rates to Money Market Rates (KIBOR)}

To estimate the degree of pass-through from policy rates to money market rates, we take into account all the possible combination of three different proxies of policy rates and four different tenors of money market rates (i.e., one-week, 1-month, 3-month, and 6 -month KIBOR).

Based on Schwartz-Bayesian Criterion (SBC), LM test for the presence of serial correlation, it was found that ARDL $(1,1)$ model is the best fit in most of the cases. Although presence of serial correlation in few regressions undermines the efficiency of OLS estimators, we consider it as a cost of maintaining comparability across regressions. Therefore, the specification is kept unchanged at order $(1,1)$ in all regressions in a bid to preserve comparability across regressions.

Table 4: F-Statistics for Testing Long Run Relationship

\begin{tabular}{lccc}
\hline & \multicolumn{2}{c}{ F-Statistic } & \\
\cline { 2 - 4 } & \multicolumn{1}{c}{ T-bills Rates } & Overnight Rate & Policy Rate \\
\hline KIBOR 1-week & $12.50^{*}$ & $7.84^{*}$ & 1.80 \\
KIBOR 1-month & $8.81^{*}$ & $6.33^{*}$ & 1.11 \\
KIBOR 3-month & $6.50^{*}$ & $5.51^{* *}$ & 1.07 \\
KIBOR 6-month & $5.91^{*}$ & $5.11^{* *}$ & 1.08 \\
\hline Note: Asymptomatic Critical values at 1\% 4.29, 5.61 and 5\% are 3.23 and 4.35 \\
* indicates significant at 1 percent, while ** indicate significant at 5 percent.
\end{tabular}

\begin{tabular}{|c|c|c|c|}
\hline & Volume 10 & Number 1 & Journal of Independent Studies and Research - MSSE \\
\hline
\end{tabular}


We test for the existence of long run relationship by using 'bounds tests'. The results of Wald-tests reported in Table 4 indicate that long run relationship exists between Tbill rates and all tenors of money market as all values of F-statistic are considerably greater than the asymptotic critical value of upper bound. The same is also the case for long run relationship between overnight rate and the KIBOR. However, there is no evidence of cointegration between the SBP policy rate and money market rate over the period of estimation. This apparently surprising result is understandable given the infrequent changes in policy rate due to its administered nature, and incorporating the period of July 2003 to July 2005 (see section 5.3) in the estimation process. The parameters of unrestricted ARDL models are used to calculate the degree of passthrough (for both the short run and the long run) and the approximate time required to reach the long run equilibrium (Table 5 ) by using techniques specified in section 6 .

- Diagnostic of unrestricted ARDL model reveals that 6-month T-bills cut-off rates is an important component of the monetary transmission mechanism over the period of estimation. It has swift pass-through to all tenors of money market rates and the long run degree of pass-through is close to one. The results also indicate that it takes less than two months to reach the degree of long run pass-through for money market rates of all tenors. Specifically, a 100 bps change in T-bills cut-off rates has an immediate impact (during a month) of 74 to 82 bps on money market rates (1month to 6-month KIBOR).

- Compared to T-bill cut-off rate, the impact of changes in weighted average overnight rates is largely confined to lower end of the yield curve (i.e., up to one week KIBOR). Specifically, a 100 bps change in overnight rate will have 61 bps changes in one week KIBOR during a month (see Table 5). The same change in overnight rate has negligible impact on 3 and 6 months KIBOR rates. In other words, pass-through of overnight rate to money market rates of one month and over is not only sluggish, but incomplete also.

\begin{tabular}{|c|c|c|c|}
\hline & Short Run & Long Run & Approximate \\
\hline \multicolumn{3}{|c|}{ Pass-through of 6-m T-bills Cut Off Rate to KIBOR } & Time (months) \\
\hline One Week & 0.736 & 0.938 & 1.275 \\
\hline One Month & 0.816 & 0.992 & 1.216 \\
\hline Three Months & 0.828 & 0.961 & 1.161 \\
\hline Six Months & 0.804 & 0.931 & 1.158 \\
\hline \multicolumn{4}{|c|}{ Pass-through Overnight rate to Market Rates } \\
\hline One Week & 0.609 & 0.914 & 1.499 \\
\hline One Month & 0.146 & 0.754 & 5.175 \\
\hline Three Months & 0.014 & 0.576 & 42.015 \\
\hline Six Months & 0.009 & 0.516 & 55.346 \\
\hline
\end{tabular}

\subsection{Pass-through of Money Market Rates to Retail Bank Rates}

Now we explore the impact of changes in money market rates on retail bank rates (both lending and deposit rates). Estimation of unrestricted ARDL models and related diagnostics indicate that models are well specified in most of the cases (few regressions which suffered from the problem of serial correlation are re-estimated by increasing the lag length of the model).

\begin{tabular}{llll|l}
\hline Journal of Independent Studies and Research - MSSE & Volume 10 & Number 1 & January 2012 & 107
\end{tabular} 
The estimation of conditional ARDL-ECM is followed by the bounds tests for exploring the possibility of long run relationship between the retail rates of the banking system and the money market rates of different tenors. Test statistics indicate the co-movement of retail banks and money market rates over the period of estimation (see Table 6).

Table 6: F-Statistics for Testing Long Run Relationship

\begin{tabular}{|c|c|c|c|c|}
\hline \multicolumn{5}{|c|}{ F-Statistic (KIBOR) } \\
\hline & 1-week & 1-month & 3-month & 6-month \\
\hline Lending rate Marginal & $9.98^{*}$ & $7.21^{\star}$ & $9.20^{*}$ & $9.98^{*}$ \\
\hline Lending Rate-outstanding & $6.65^{\star}$ & $8.14^{\star}$ & $11.90^{*}$ & $10.75^{\star}$ \\
\hline Deposit rate-marginal & $10.12^{*}$ & $8.62^{*}$ & $9.29^{*}$ & $9.17^{*}$ \\
\hline Deposit rate-Outstanding & $4.11^{\star \star *}$ & $8.75^{\star}$ & $14.40^{*}$ & $14.95^{*}$ \\
\hline
\end{tabular}

Note: Asymptomatic Critical values at $1 \% 4.29,5.61$ and $5 \%$ are 3.23 and 4.35

${ }^{*}$ indicates significant at 1 percent, ${ }^{* *}$ indicate significant at 5 percent, ${ }^{* * *}$ indicate significant at 10 percent.

Table 7: Pass-through of Money market Rates to Banks' Retail Rates

Pass-through of 1-week KIBOR Short Run Long Run Approximate Time

Lending Rates-Marginal

Lending rates-Outstanding

0.30

0.05

0.13

Deposit rates-Outstanding

Pass-through of 1-month KIBOR

Lending Rates-Marginal

Lending rates-Outstanding

Deposit rates-Fresh

Deposit rates-Outstanding

Pass-through of 3-month KIBOR

Lending Rates-Marginal

Lending rates-Outstanding

Deposit rates-Fresh

Deposit rates-Outstanding

Pass-through of 6-month KIBOR

Lending Rates-Marginal

Lending rates-Outstanding

Deposit rates-Fresh

Deposit rates-Outstanding

0.14

0.44

0.29

0.15

$\begin{array}{ll}0.91 & 3.08 \\ 0.25 & 5.46 \\ 0.64 & 5.06 \\ 0.60 & 15.07 \\ 0.91 & 2.39 \\ 0.27 & 3.14 \\ 0.60 & 2.72 \\ 0.65 & 5.53 \\ 0.92 & \\ 0.29 & 2.39 \\ 0.60 & 2.80 \\ 0.68 & 2.24 \\ 0.96 & 4.85 \\ 0.34 & \\ 0.61 & 2.18 \\ 0.71 & 3.50 \\ & 2.13 \\ & 4.80\end{array}$

5.46

5.06

15.07

2.39
3.14

2.72

2.39

2.80

2.24

2.18

0.71

2.13

0.38

$0.09 \quad 0.27$

$0.22-0.60$

$0.12-0.65$

$0.38 \quad 0.92$

$0.10 \quad 0.29$

These results indicate that following points are worth noting.

1) The pass-through of money market rates to weighted average lending rate (on fresh loans) is approximately close to one (see Table 7). Specifically, a 100 bps change in 6-month KIBOR will lead to 96 bps change in lending rates in the long run. Almost half of this pass-through is completed during first month of the change.

2) Compared to responsiveness of the lending rate on fresh loans, pass-through of money market rates to lending rate on outstanding is not only sluggish, but also incomplete. Specifically, a 100 bps change in 3-month KIBOR has an immediate (during a month) impact of 10 bps on the weighted average lending rates on outstanding loans. Its long run impact turns out to be only $29 \mathrm{bps}$, which is nowhere close to the change of $100 \mathrm{bps}$.

3) Pass-through from money markets to deposit rates is also sluggish and incomplete. Within different money market rates, the results indicate that returns on fresh deposits

108 January $2012 \quad$ Volume $10 \quad$ Number $1 \quad$ Journal of Independent Studies and Research - MSSE 
are relatively more responsive to changes in KIBOR of 1 to 6 -month tenors. The long run impact is hovering around $60 \mathrm{bps}$, while the immediate response is in the range of 13 to $29 \mathrm{bps}$.

\subsection{Possibility of Asymmetric Impact}

It is generally perceived that Pakistani banks follow different time paths for adjusting their lending and deposit rates in response to increasing and decreasing interest rate scenarios. To explore this possibility over the study period, we followed the methodology of Cottarelli and Kourelis (1994), Borio and Fritz (1995) and Mojon (2000). Specifically, overall sample period is divided into two sub-samples: (1) policy rate is flat or increasing; and (2) policy rate is flat or decreasing.

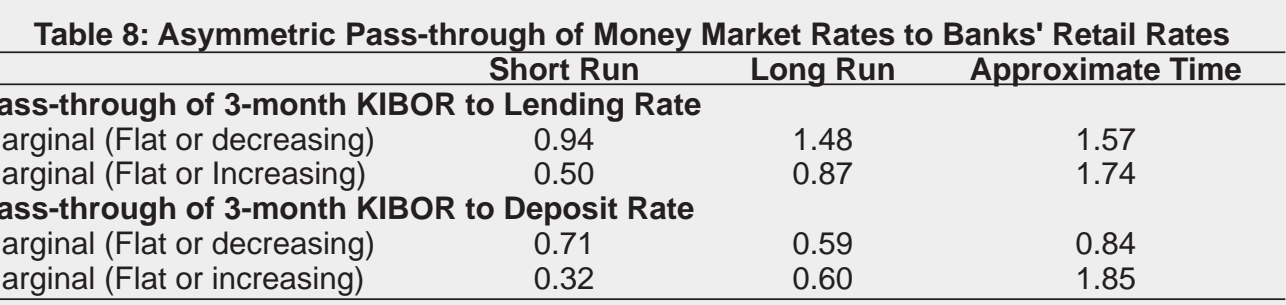

To quantify these differences, we run separate unrestricted ARDL models based on two subsamples. For the sake of brevity, we confined our analysis to impact of 3-month KIBOR on both the marginal lending and deposit rates. The results confirm our expectation that adjustment in both lending and deposit rates adjust differently when market interest rates are increasing or decreasing (see Table 8). Specifically, in a decreasing interest rate scenario, the pass-through to lending rate is greater than in case of decreasing interest rate scenario. This is contrary to the popular perception at least on face value.

However, these are understandable if seen in the context of banks' overall loan portfolio. First, the corporate sector is the biggest borrower, which generally has the power to bargain with the banking system. Second, major portion of private sector loans is for the working capital. Here again, the corporate sector has the opportunity to repay their working capital and re-negotiate on new terms. Finally, the relatively greater competition among banks for extending loans (especially to the corporate sector) plays its role in setting their lending rate differently in case of increasing or decreasing interest rate scenario.

\section{Conclusion}

This study investigates the impact of changes in State Bank of Pakistan's policy rate on money market and retails rates of the banking system. We use monthly time series data on key interest rates from July 2001 to August 2011, to estimate unrestricted autoregressive error correction model (ARDL-ECM). To explore dynamics of different interest rates, SBP monetary policy rate, T-bill cut-off rates and weighted average overnight rate are used proxies for the policy rates. Among the money market rate, KIBOR of different tenors is used as the pass-through from very short term money market rates (1-Week or 1-month KIBOR) can differ from that of 3 to 6 - month KIBOR on the retail rates of banks. Similarly, we used two type of lending and deposit rates each (outstanding as well as fresh).

\begin{tabular}{llll|l}
\hline Journal of Independent Studies and Research - MSSE & Volume $10 \quad$ Number $1 \quad$ January 2012 & 109
\end{tabular}


For estimation, we use two-stage procedure to analyze dynamics among the interest rates. At first stage, we explore the pass-through of changes in policy rates to money market rates. The results indicate cut-off rate of T-bills emerged as the most important link in transmitting changes in policy rate to money market rates. Specifically, a long run equilibrium relationship exists between T-bills cut-off rate and KIBOR of all tenors. The long run impact is one-to-one and a 100 bps change in policy rate has an immediate (during a month) impact of around $80 \mathrm{bps}$ on KIBOR of all tenors. It implies that full impact is realized in less than two months period.

In the second stage, we explored pass-through of changes in money market rates to banks' lending and deposit rates. The results indicate that lending rates on fresh loans are more responsive to changes in money market rates compared to the lending rates on outstanding loans. Specifically, a 100 bps change in KIBOR of different tenor leads to 91 to 96 bps change in lending rate on fresh loans. In terms of time, it takes two-tothree months to achieve full impact.

Compared to lending rates, pass-through of changes in money market rates to deposit rates is not only sluggish but incomplete as well. Response of returns on fresh deposits is confined to only 60 bps only due to 100 bps change in money market rates. Moreover, it takes two-to six months to realize this impact.

Finally, there is evidence in favour of asymmetric pass-through of money rates to banks' lending and deposit rates. Both lending and deposit rates follow different time paths in decreasing and increasing policy rate scenarios. 


\section{References}

Asif, I. Agha, N. Ahmed, Y. A. Mubarik, H. Shah 2005, 'Transmission Mechanism of Monetary Policy in Pakistan', SBP-Research Bulletin, Vol. 1, No. 1, pp. 1-23.

Borio, Claudio, E. V., and W. Fritz 1995, The Response of Short-Term Bank Lending Rates to Policy Rates: A Cross Country Perspective, Bank for Intentional Settlement.

Bernanke, B. 1993, 'Credit in Macroeconomy', Federal Reserve Bank of New York Quarterly Review, Vol. 78, pp. 435-45.

Bernanke, B., and Blinder, Alan S. 1988, 'Credit, Money, and Aggregate Demand', The American Economic Review, Vol. 78, No. 2, pp. 435-39.

Bernanke, B. and Gertler M. 1989, 'Agency Cost, Net Worth, and Business Fluctuations,' The American Economic Review, Vol. 79, pp. 14-31.

Bernanke, B. and Gertler M. 1995, 'Inside the Black Box: The Credit Channel of Monetary Policy Transmission,' Journal of Economic Perspectives, Vol. 9, No. 4, pp. 27-48.

Bernanke, B. and Gilchrist S. 1999, 'The Financial Accelerator in a Quantitative Business Cycle Framework,' in Handbook of Macroeconomics, edited by M. Woodford and J.B. Taylor, Elsevier Science, Amsterdam.

Bondt, G. 2002, 'Retail Bank Interest Rate Pass-through: New Evidence at the Euro Area Level,' Working paper \# 132. Frankfurt: European Central Bank.

Cottarelli, C., and A. Kourelis, 1994, 'Financial Structure, Bank Lending Rates, and Transmission Mechanism of Monetary Policy,' IMF Staff Paper, Vol. 41, No. 4, pp. 587-623.

Goodfriend, M., 1991, Interest Rates and the Conduct of Monetary Policy. CarnegieRochester Conference Series on Public Policy, Elsevier, Vol. 34, No. 1, pp. 7-30.

Hanif, M. Nadim, M. A. K. Lodhi, M. H. Khan, Z. Hyder, Irem B. and Ansari S. 2010, 'A Small Size Macroeconometric Model for Pakistan Economy,' State Bank of Pakistan, Working Papers \# 34.

Khan, Ashfaque H. 1994, 'Financial Liberalization and Demand for Money in Pakistan,' Pakistan Development Review, Vol. 33, No. 4, pp. 997-1010.

Khawaja, Idrees and Khan S. 2008, 'Pass-through of Change in Policy Interest Rate to Market Rates', Pakistan Development Review, Vol. 47, No. 4, pp. 661-674.

Khan, M. Aslam, M. Farooq Arby, and M. Amin K. Lodhi 2000, "Disaggregated Approach for Modeling Demand for Money in Pakistan", Pakistan Journal of Applied Economics, Vol. 16, No. 1/2 \& 2, pp. 95-77.

Moinuddin 2007, Choice of Monetary Policy Regime: Should SBP Adopt Inflation Targeting? State Bank of Pakistan, Working Papers \# 19.

\begin{tabular}{llll|l}
\hline Journal of Independent Studies and Research - MSSE & Volume 10 & Number 1 & January 2012 & 111
\end{tabular} 
Mojon, B. 2000, 'Financial Structure and the Interest Rate Channel of the ECB Monetary Policy,' Working paper 40. Frankfurt: European Central Bank.

Pesaran, M. H., Y. Shin, Smith R. J. 2001, Bounds Testing Approaches to the Analysis of Level of Relationship, www.econ.cam.ac.uk/

Qayyum, A., S. Khan, and Khawaja I. 2005, 'Interest Rate Pass-through in Pakistan: Evidence from Transfer Function Approach', Pakistan Development Review, Vol. 44, No. 4, pp 975-1001.

State Bank of Pakistan 2005, Performance of the Banking Sector, Pakistan: Financial Sector Assessment, pp. 45-59.

Sanusi, A. R. 2010, Interest Rate Pass-Through and Efficiency of Monetary Policy in Nigeria: 2002-2010 http://ssrn.com/abstract=1782172.

Sassanpour, C. and Moinuddin 1993, 'Experiments with Demand for Money Functions for Pakistan', Statistical Bulletin, State Bank of Pakistan, July.

Tieman, Alexander 2004, 'Interest Rate Pass-Through in Romania and Other Central European Economies,' IMF Working Paper, WP/04/201. 